\section{Radon and thoron exhalation rate measurements from building materials used in Serbia}

\author{
Igor T. Čeliković $\mathbb{0}$, \\ Gordana K. Pantelić (1), \\ Miloš Z. Živanović $\mathbb{C}^{\circ}$, \\ Ivana S. Vukanac $\mathbb{C}$,

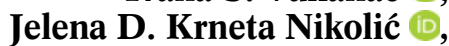 \\ Aleksandar B. Kandić, \\ Boris B. Lončar
}

\begin{abstract}
The second most important source of indoor radon, after soil beneath dwelling, is building material. With the increase in environmental awareness and new energy-saving policies, residents tend to replace the existing windows with tighter windows, which leads to a decrease in air exchange rate and consequently an increase in indoor radon concentration. In case of low exchange rates, dose caused by inhalation of radon and its progeny can exceed external dose originating from the radium content in the surrounding building material. In this paper, surface exhalation rates of radon $\left({ }^{222} \mathrm{Rn}\right)$ and thoron $\left({ }^{220} \mathrm{Rn}\right)$ from typical building materials used for construction and interior decoration of houses in Serbia were investigated. Surface exhalation rate measurements were performed using the closed-chamber method, while concentrations of radon and thoron in the chamber were continuously measured using an active device, RTM1688-2, produced by SARAD ${ }^{\circ}$ GmbH. Finally, the impact of the replacement of windows on the indoor radon concentration was estimated.
\end{abstract}

Keywords: Air exchange rate $\cdot$ Building materials - Radon exhalation rate

I. T. Čelikovićø, G. K. Pantelić, M. Z. Živanović,

I. S. Vukanac, J. D. Krneta Nikolić, A. B. Kandić "Vinča" Institute of Nuclear Sciences

University of Belgrade

Mike Petrovića Alasa 12-14, 1100 Belgrade, Serbia

E-mail: icelikovic@vin.bg.ac.rs

\section{B. B. Lončar}

Faculty of Technology and Metallurgy

University of Belgrade

Karnegijeva 4, 11000 Belgrade, Serbia

Received: 2 December 2019

Accepted: 20 January 2020

\section{Introduction}

Based on the extensive studies of influence of radon and its progeny on uranium (and non-uranium) miners, radon was recognized as a human carcinogen in 1988 by the International Agency for Research on Cancer (IARC) [1]. A few decades later, pooling of radon studies performed in China, Europe and North America revealed unambiguous link between indoor radon and lung cancer, and consequently, World Health Organization (WHO) has identified radon as the second leading cause of lung cancer after smoking, being responsible for $3-14 \%$ of all lung cancers [2].

The European Council has laid down new basic safety standards (BSS) for the protection against the dangers arising from exposure to ionizing radiation [3]. In accordance with the Council Directive 2013/59/Euratom (BSS), member states are obliged to investigate the exposure of members of the public and workers to indoor radon to develop a radon action plan and to inform the public about radon levels they are exposed to. This has led to an increase in radon-related activities in recent years and to an increased number of measurements of indoor radon concentrations.

The main source of indoor radon is soil subjacent to a dwelling. Although a typical contribution of soil gas to indoor air gas is $1 \%$, soil gas can contribute with more than $10 \%$ to indoor air in houses that 
are built on permeable soil or with a poor foundation (lots of cracks, bad junctions between walls and floor, etc.) [4]. The second most important source of indoor radon is building material. In recent years, the contribution of radon from the building material has been becoming more important because of the new trends regarding energy saving and energy efficiency in the construction industry. Replacing the old windows with new ones that provide better isolation is especially important. Typically, single glazed, wooden framed windows are being replaced by double glazed unplasticized polyvinyl chloride (UPVC), which leads to a reduction in air exchange rate [5]. Reduced air exchange rate leads to an increase in indoor radon concentration [6].

In this paper, the results of the surface exhalation rate of radon $\left({ }^{222} \mathrm{Rn}\right)$ and thoron $\left({ }^{220} \mathrm{Rn}\right)$ from some typical building materials used for construction and decoration of houses in Serbia are presented. Exhalation rate measurements were performed using the closed-chamber method. The concentrations of radon and thoron in the chamber were continuously measured using RTM1688-2, produced by SARAD ${ }^{\circledR}$ $\mathrm{GmbH}$. The impact of the replacement of windows on the indoor radon concentration was estimated based on available literature data. This work represents a continuation of research project activities in which mass exhalation of building materials and different parameters influencing exhalation were studied. Results of previous research were published in conference proceedings [7].

\section{Materials and methods}

The exhalation rates from various building materials commonly used is Serbia were measured. Nine different building materials were chosen for the analysis. The attention was paid to cover the representative types of building materials. Therefore, bricks and brick blocks based on clay and concrete were used. Decorative materials, such as facade brick, natural stone, granite and marble, were analysed. Finally, samples of two materials, which are commonly used for thermal insulation, were analysed as well.

A chamber with a volume of $30 \mathrm{dm}^{3}$ was used for the measurement of radon exhalation rate. All materials were cut in well-defined shape in order to easily calculate exhalation area and to fit the dimension of the accumulation chamber. Exhalation area of the samples ranged from $2.5 \times 10^{-2} \mathrm{~m}^{-2}-6.7 \times 10^{-2} \mathrm{~m}^{-2}$, while the mass ranged from $260 \mathrm{~g}$ to $670 \mathrm{~g}$. Samples prepared in this way were placed in the accumulation chamber and sealed for approximately one week, before each measurement started. The method used for the measurement of exhalation rate is well known as the closed-chamber method [8].

According to this method, the exhalation rate can be determined by measuring the accumulation of radon in time using the following equation [9]:

$$
C(t)=\frac{E_{S} S}{V \lambda}\left(1-e^{\lambda t}\right)+C_{0} e^{-\lambda t}
$$

where $C(t)$ is the measured ${ }^{222} \mathrm{Rn}$ concentration in the accumulation chamber $\left[\mathrm{Bq} \cdot \mathrm{m}^{-3}\right]$ at the time $t, E_{S}$ is the surface exhalation rate $\left[\mathrm{Bq} \cdot \mathrm{m}^{-2} \cdot \mathrm{s}^{-1}\right], S$ is the exhaling area of the sample $\left[\mathrm{m}^{2}\right], V$ is the volume of the chamber $\left[\mathrm{m}^{3}\right], \lambda$ is the radon decay constant $\left[\mathrm{s}^{-1}\right]$ and $C_{0}$ is the initial radon concentration in the chamber $\left[\mathrm{Bq} \cdot \mathrm{m}^{-3}\right]$.

Exhaling of radon from a sample in the chamber can be suppressed partly due to a leakage of radon from the chamber (chamber not being perfectly sealed) and partly due to back-diffusion (a decrease in exhalation due to an increase in radon concentration in the chamber). In this case, the decay constant can be expressed as the effective decay constant using the following equation: $\lambda_{\text {eff }}=\lambda+\lambda_{l}+\lambda_{b}$, where $\lambda_{l}$, and $\lambda_{b}$ take into account the removal of ${ }^{222} \mathrm{Rn}$ due to leakage and back-diffusion, respectively [9].

In order to measure the effective decay constant, a dedicated experiment was performed. A test sample with a high ${ }^{226} \mathrm{Ra}$ content was used as an exhalation material to ensure high radon concentrations in the chamber and thus reduce the uncertainties of the acquired data. The test sample was placed in the chamber, and radon concentration in the chamber was continuously measured for approximately 16 days with the averaging period of $4 \mathrm{~h}$. The effective decay constant was deduced by fitting Eq. (1) to the obtained data and was afterwards used for the calculation of radon surface exhalation rate.

The same closed-chamber method was used for the measurement of thoron's exhalation rate as well. Small differences were introduced due to a much shorter half-life of thoron (55.8 s) compared to that of radon (3.82 days). A smaller chamber with a volume of $1.7 \mathrm{dm}^{3}$ was used, and the sampling time was set to $15 \mathrm{~min}$, which is more than 15 times larger than the thoron half-life. This time is sufficient to achieve constant thoron concentration and for any thoron present in the chamber before the measurement to completely decay. Thoron concentration in the chamber is represented by the following equation:

$$
C_{\mathrm{Tn}}=\frac{E_{S} S}{V \lambda_{\mathrm{Tn}}}
$$

where $C_{\mathrm{Tn}}$ is the thoron concentration and $\lambda_{\mathrm{Tn}}$ is the thoron decay constant.

Build-up of radon and thoron in the chamber was measured using active device RTM1688-2, which has a sensitivity of $6.5 \mathrm{cts} /\left(\mathrm{min} \cdot \mathrm{kBq} \cdot \mathrm{m}^{-3}\right)$.

\section{Results and discussion}

Accumulation of radon in the chamber, due to radon exhalation from the test sample with a high ${ }^{226} \mathrm{Ra}$ concentration, during 16 days of measurement, with $4 \mathrm{~h}$ of averaging period, is shown in Fig. 1. Equation (1) was fitted to the experimental data, keeping $E_{S}, \lambda_{\text {eff }}$ and $C_{0}$ as free parameters.

Based on the fit, the initial radon concentration in the chamber, $C_{0}$, was $0 \pm 13 \mathrm{~Bq} \cdot \mathrm{m}^{-3}$, which is not surprising since the chamber was closed in the "radon-free" environment. The volume of the chamber was much larger than the volume of the 


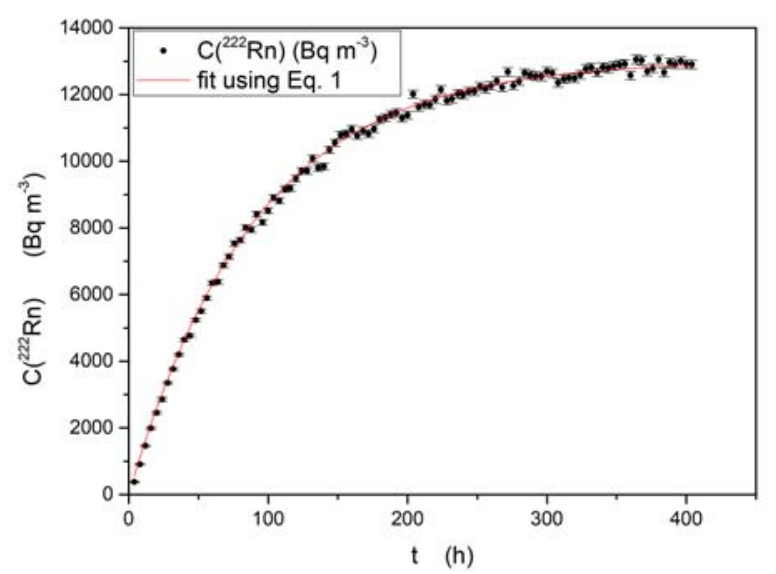

Fig. 1. Radon concentration in the chamber due to exhalation from the test sample with a high ${ }^{226} \mathrm{Ra}$ content. Theoretical build-up curve according to Eq. (1) was fitted to the data and is also shown.

sample, and therefore, back-diffusion can be neglected [10]. Fitted effective decay constant was $\lambda_{\text {eff }}=(305.6 \pm 3.6) \times 10^{-8} \mathrm{~s}^{-1}$, which showed that there was a certain leakage of radon from the chamber. The contribution of leakage to decay constant was approximately $\lambda_{l}=7.02 \times 10^{-7} \mathrm{~s}^{-1}$.

Radon surface exhalation rates for all sample materials and the fitted effective decay constant value were calculated using Eq. (1). Results for both radon and thoron exhalation rates for selected building materials are presented in Table 1.

Large ranges of radon and thoron surface exhalation rates from different materials were observed. Additional research is required in order to better understand these results, especially on radium content in building materials, as well as their porosity and permeability. Measured radon exhalation rates are between $15.8 \mu \mathrm{Bq} \cdot \mathrm{m}^{-2} \cdot \mathrm{s}^{-1}$ and $1380 \mu \mathrm{Bq} \cdot \mathrm{m}^{-2} \cdot \mathrm{s}^{-1}$, while thoron exhalation rates are between $<1.5 \mathrm{mBq} \cdot \mathrm{m}^{-2} \cdot \mathrm{s}^{-1}$ and $337 \mathrm{mBq} \cdot \mathrm{m}^{-2} \cdot \mathrm{s}^{-1}$. The data are in agreement with previously published results [11].

The indoor radon concentration originating only from the building material can be estimated using the following simple equation [12]:

$$
C_{\mathrm{Rn}}=\frac{E_{S} S}{V \lambda_{V}}
$$

where $\lambda_{V}$ is the ventilation rate $\left[\mathrm{h}^{-1}\right]$ and $S / V$ is the surface to volume ratio $\left[\mathrm{m}^{-1}\right]$ of the room. For standard room model, $S / V$ is $1.6 \mathrm{~m}^{-1}$.

Table 1. Radon and thoron surface exhalation rates from selected building materials

\begin{tabular}{lcc}
\hline \multicolumn{1}{c}{ Sample } & $\begin{array}{c}E_{S}\left({ }^{222} \mathrm{Rn}\right) \\
{\left[\mathrm{mBq} \cdot \mathrm{m}^{-2} \cdot \mathrm{s}^{-1}\right]}\end{array}$ & $\begin{array}{c}E_{S}\left({ }^{220} \mathrm{Rn}\right) \\
{\left[\mathrm{mBq} \cdot \mathrm{m}^{-2} \cdot \mathrm{s}^{-1}\right]}\end{array}$ \\
\hline Brick & $0.090 \pm 0.018$ & $32.3 \pm 2.9$ \\
Brick block & $0.340 \pm 0.055$ & $58.8 \pm 9.4$ \\
Concrete block & $0.610 \pm 0.016$ & $111 \pm 20$ \\
Facade brick & $0.146 \pm 0.073$ & $26.3 \pm 9.5$ \\
Thermal block & $1.380 \pm 0.071$ & $31.6 \pm 8.5$ \\
Natural stone & $0.197 \pm 0.026$ & $337 \pm 37$ \\
Concrete styrofoam & $0.658 \pm 0.034$ & $60 \pm 14$ \\
Marble & $0.0158 \pm 0.0066$ & $<1.5$ \\
Granite & $0.0336 \pm 0.0027$ & $42.3 \pm 2.1$ \\
\hline
\end{tabular}

According to the data from the United Nations Scientific Committee on the Effects of Atomic Radiations (UNSCEAR) sources, the common range of ventilation rates in dwellings is in the interval of $0.2-2 \mathrm{~h}^{-1}$, with a geometrical mean of $0.63 \mathrm{~h}^{-1}$ [13]. It was shown by Oreszczyn et al. that the installation of modern windows reduces air exchange rate by 0.23 exchanges per hour [5], which can cause a significant increase in indoor radon concentration if proper building materials are not used.

Owing to a lack of data for Serbia, the value of exhalation rate of $0.63 \mathrm{~h}^{-1}$ is the same as the world average mean. Contribution to indoor radon concentration due to exhalation from building material with the highest exhalation rate (thermal block) would be $13 \mathrm{~Bq} \cdot \mathrm{m}^{-3}$. If we assume that replacement of old windows and doors will cause the same reduction of air exchange rate by $0.23 \mathrm{~h}^{-1}$ as in the case of UK [5], the contribution to indoor radon concentration would thus be $20 \mathrm{~Bq} \cdot \mathrm{m}^{-3}$, or in relative terms, it will cause an increase in radon concentration by $35 \%$, which in extreme cases could be severe.

\section{Conclusion}

In this manuscript, the results of the radon and thoron surface exhalation rate measurements from several common building materials used in Serbia are presented. Data were obtained using the closed-chamber method, and radon and thoron measurements were performed using an active device RTM1688-2. The results that were obtained indicate a large range of exhalation rates for different materials. Consequently, some of them could cause a significant increase in indoor radon concentration. This is especially important when modern exterior joinery, windows and doors are installed in residential buildings, significantly reducing the ventilation rate. Therefore, it is important to monitor the radon exhalation rate from the material used in modern construction.

Acknowledgment. The research was supported by the Ministry of Education, Science and Technological Development of Serbia under projects OI 171018, OI 171007 and III 43009.

\section{ORCID}

I. T. Čeliković (1) http://orcid.org/0000-0002-5642-4393 J. D. Krneta Nikolić (10 http://orcid.org/0000-0003-3233-1149

G. K. Pantelic (D) http://orcig.org/0000-0002-3728-652X

I. S. Vukanac (D) http://orcid.org/0000-0002-1225-250X M. Z. Živanović (D http://orcid.org/0000-0003-2965-1897

\section{References}

1. International Agency for Research on Cancer. (1988). Manmade mineral fibres and radon. (IARC Monographs on the Evaluation of Carcinogenic Risks to Humans, Vol. 43). Lyon, France: IARC. 
2. World Health Organization. (2009). WHO Handbook on indoor radon: A public health perspective. Geneva: WHO. Available from https://www.ncbi.nlm.nih.gov/ books/NBK143222/.

3. European Union. (2013). Council Directive 2013/59/ Euratom of 5 December 2013 laying down basic safety standards for protection against the dangers arising from exposure to ionising radiation, and repealing Directives 89/618/Euratom, 90/641/Euratom, 96/29/ Euratom, 97/43/Euratom and 2003/122/Euratom. Official Journal of the European Union, OJ L13, 17.1.2014, 1-73. https://eur-lex.europa.eu/legalcontent/EN/TXT/?uri=OJ:L:2014:013:TOC.

4. World Health Organization. (2010). Guidelines for indoor air quality: Selected pollutants. Copenhagen, Denmark: WHO Regional Office for Europe.

5. Oreszczyn, T., Mumovic, D., Ridley, I., \& Davies, M. (2005). The reduction in air infiltration due to window replacement in UK dwellings: Results of a field study and telephone survey. Int. J. Vent., 4(1), 71-77. DOI: 10.1080/14733315.2005.11683700.

6. Yarmoshenko, I. V., Vasilyev, A. V., Onishchenko, A. D., Kiselev, S. M., \& Zhukovsky, M. V. (2014). Indoor radon problem in energy efficient multi-storey buildings. Radiat. Prot. Dosim., 160, 53-56. DOI: 10.1093/ $\mathrm{rpd} / \mathrm{ncu} 110$.

7. Avramović, D., Čeliković, I., Ujić, P., Vukanac, I., Kandić, A., Jevremović, A., Antonijević, D., \& Lončar, B. (2018). Radon exhalation rate of some building materials common in Serbia. In RAD 2018 Proceedings: 6. International Conference on Radiation and Applications in Various Fields of Research, 18-22 June 2018,
Ohrid, Macedonia (Vol. 3, pp. 119-122). Niš, Serbia: RAD Association. DOI: 10.21175/RadProc.2018.26.

8. Abu-Jarad, F. A. (1988). Application of nuclear track detectors for radon related measurements. Nucl. Tracks Radiat. Meas., 15(1/4), 525-534. DOI: 10.1016/1359-0189(88)90195-1.

9. Ujić, P., Čeliković, I., Kandić, A., \& Žunić, Z. (2008). Standardization and difficulties of the thoron exhalation rate measurements using an accumulation chamber. Radiat. Meas., 43(8), 1396-1401. DOI: 10.1016/j.radmeas.2008.03.003.

10. Poffijn, A., Bourgoignie, R., Mirijins, R., Uyttenhove, J., Janssens, A., \& Jacobs, R. (1984). Laboratory measurements of radon exhalation and diffusion. Radiat. Prot. Dosim. 7, 77-79.

11. Ujic, P., Celikovic, I., Kandic, A., Vukanac, I., Djurasevic, M., Dragosavac, D., \& Zunic, Z. S. (2010). Internal exposure from building materials exhaling ${ }^{222} \mathrm{Rn}$ and ${ }^{220} \mathrm{Rn}$ as compared to external exposure due to their natural radioactivity content. Appl. Radiat. Isot., 68, 201-206. DOI: 10.1016/j.apradiso.2009.10.003.

12. Stoulos, S., Manolopoulou, M., \& Papastefanou, C. (2003). Assessment of natural radiation exposure and radon exhalation from building materials in Greece. J. Environ. Radioact., 69(3), 225-240. DOI: 10.1016/ s0265-931x(03)00081-x.

13. United Nations Scientific Committee on the Effects of Atomic Radiation. (2000). Sources and effects of ionizing radiation. United Nations Scientific Committee on the Effects of Atomic Radiation UNSCEAR 2000 Report to the General Assembly, with Scientific Annexes. Vol. 1: Sources. New York: United Nations. 